\title{
A beleza escondida no pobre: uma leitura de Is 53,2-3
}

\section{The beauty hidden in the poor: a reading of Is $53,2-3$}

\section{Armando Rafael Castro Acquaroli*}

Recebido em: 26/07/2019. Aceito em: 21/02/2020.

Resumo: O presente artigo procura resgatar a beleza que está escondida no pobre que sofre. Enquanto a sociedade tenta escondê-lo, evitá-lo, relegá-lo à margem, o modelo do servo sofredor aponta para outro caminho. Na sociedade marcada pela associação grega entre o belo e o bom, há, muitas vezes, uma práxis na qual o olhar é carregado de preconceitos diante dos que não se enquadram nos paradigmas modernos. Para romper com isso, apresentamos o servo sofredor de Isaías, que usa a categoria do silêncio militante. Esse não se contenta com a resignação de quem sabe que nada mudará, mas provoca com sua atitude a uma práxis libertadora.

Palavras-chave: Pobre. Beleza. Servo.

Abstract: This article seeks to rescue the beauty that is hidden in the poor who suffer. While society tries to hide it, avoid it, relegate it to the margins, the model of the suffering servant points to another path. In the society marked by the Greek association between the beautiful and the good, there is often a praxis in which the gaze is loaded with prejudices against those who do not fit into the modern paradigms. To break with this, we have the suffering servant of Isaiah, who uses the category of militant silence. He is not content with the resignation of those who know that nothing will change, but provokes with his attitude to a liberating praxis.

Keywords: Poor. Beauty. Servant

* Doutorando em Teologia Bíblica (Pontificia Università Gregoriana, Roma). Mestre em Teologia Bíblica (Pontificia Università Gregoriana, Roma, 2017). Bacharel em Filosofia (Faculdade São Luiz, Brusque, 2009). Bacharel em Teologia (Instituto Teológico de Santa Catarina, Florianópolis, 2014). Presbítero da Diocese de Joinville (SC).

E-mail: castroacquaroli@gmail.com

Lattes: 4684045215794300 


\section{Introdução}

A beleza é algo que atrai o ser humano desde os seus primeiros passos. Seu antípoda, a feiura, também sente os efeitos de sua condição fazendo, porém, com que evitemos o que não é agradável aos nossos olhos. As pessoas mais simples de nossa sociedade com frequência têm menos oportunidade de «aparecer» belas e, consequentemente, não raro, são pessoas de quem desviamos a atenção. Um fenômeno interessante que ilumina nossa realidade é a experiência do servo sofredor, descrito sem beleza e como alguém repugnante. Seu exemplo nos indica o caminho do silêncio militante que combate o jugo da opressão e o liberta das cadeias da ditadura da beleza.

\section{O bom e o belo}

Entre os antigos hebreus e os antigos gregos a distinção entre o "bom" e o "belo" não existia. Em hebraico, o termo tob se refere àquelas qualidades que tornam o objeto desejável, significando tanto o bom quanto o belo ${ }^{1}$. Assim, por exemplo, a serpente diz a Adão e Eva: "no dia em que comerdes desse fruto, conhecereis o bem e o mal (tob wara)" (cf. Gn 3,15). Aqui é claro o contraste entre o bem e o mal e, portanto, a palavra tob é ligada ao campo semântico da "bondade". Por outro lado, antes do dilúvio, o texto bíblico diz que os "filhos de Deus viram as filhas dos homens que eram belas (tobot) e as tomaram como esposas" (Gn 6,2). Aqui o que atrai a atenção dos homens é a "beleza" das mulheres.

Em modo semelhante os gregos, em particular os estoicos, também associavam o conceito de bondade ao de beleza, mesmo tendo duas palavras distintas para cada um desses conceitos. O bomlbem se dizia agathós, e o belo, kalós. Mas ambas as palavras significavam na verdade bom $\backslash$ belo.

Nossa sociedade talvez esteja muito marcada por esse tipo de concepção de acordo com a qual, para que sejam mantidos certos valores considerados bons, é preciso aproximar-se ao máximo da beleza. Isso significa que o "feio" é repudiado e precisa ser mantido longe de nossos olhos. Isso é bem claro nos últimos filmes de super-heróis, em que os protagonistas são representados com corpos simétricos e belos, consonantes com sua conduta moral (boa). Seus antagonistas, porém, são

1 Cf. HÖVER-JOHAG, I., "טוב", GLAT, III, 367-394. 
feios, "defeituosos" e, consequentemente, maus. Ou ainda nas estruturas das cidades hodiernas em que o centro é bem desenvolvido, com prédios modernos, simetria das formas, enquanto a periferia é assimétrica e com estruturas arcaicas e decadentes. O centro aparece por ser belo, a periferia desaparece por ser feia.

É a interpretação errônea desse princípio que nos leva a cometer a ditadura da beleza. Nesse regime associa-se imediatamente aqueles que são sujos, fedidos, malvestidos, em suma, "não-belos", a pessoas cuja conduta moral é "não-boa": bandidos, safados, desonestos... Se quisermos alargar ainda mais o conceito, podemos citar os que têm a pele mais escura, "mais suja" e, por conseguinte, são cognominados pela sua falta de caráter: "todo negro é ladrão, preguiçoso, desonesto". Na melhor das hipóteses desponta a frase "é negro, mas é boa gente", como se o comportamento moral de uma pessoa fosse determinado pela característica de seu fenótipo. Infelizmente, em pleno século XXI, esse tipo de abordagem está longe de ser raro.

Mas o problema não está na identificação grega de bondade/beleza. Ao contrário, essa parece ser bastante pertinente. A dificuldade reside no fato de que não conseguimos perceber a beleza, e consequente bondade, que se esconde por trás da aparente feiura dos menos favorecidos pela sociedade.

Para nos ajudar a refletir sobre isso, é importante fazer uma pequena hermenêutica de Is 53,2-3, que fala do servo sofredor, cujo sofrimento e desprezo é figura da mesma situação experimentada por tantos pobres hoje.

\section{O homem desprezado de Is 53,2-3}

"cresceu diante dele como um rebento enraizado em terra árida. Nele não havia aparência (to'ar) nem beleza (hadar) para atrair nossos olhares, nem aspecto que nos cativasse. Desprezado e evitado pelos homens, homem sofredor, curtido na dor; ao vê-lo cobriam o rosto; desprezado, nós o tivemos por nada (lo hashab)" (Is 53,2b-3).

Nesse texto o profeta, chamado comumente Dêutero-Isaías ${ }^{2}$, está vivendo a difícil realidade do exílio. Embora tal experiência nunca

2 Para uma discussão mais detalhada sobre a delimitação do Dêutero-Isaías, vidi, MELLO, Alberto, Isaia: Introduzione, traduzione e commento, NVBTA 10, Cinisello Balsamo: San Paolo, 2012. p.12-21. 
tenha sido bem assimilada pelos deportados, tampouco se pode pensar que se tratasse de escravidão em sentido moderno para descrever o que lá aconteceu.

Os judeus após serem deportados e instalarem-se no novo território, a Babilônia, aos poucos recebiam o direito de construir casas e plantar, bem como de contrair matrimônio e gerar filhos (cf. Jr 29,5-6). Puderam agrupar-se como "povo" e formar vilas, como a de Tell-Aviv (cf. Ez 3,15), que talvez era o núcleo judaico de maior importância. Tais localidades se tornaram cada vez mais centros de vida social. Desenvolveu-se o comércio, havendo inclusive certas comodidades (cf. 2Rs 25,28). Chegou-se até mesmo a uma verdadeira riqueza por parte de alguns ${ }^{3}$.

De qualquer forma, sempre houve o sonho do retorno à pátria dos ancestrais. Então surgiram as "teses" sobre os motivos pelos quais Deus abandonara seu povo, relegando-o a uma terra estrangeira. Em modo particular, a causa dessa desfortuna residia nos pecados cometidos pelo povo (cf. $\mathrm{Br} 6,1$ et al.).

Ao mesmo tempo, foram feitos retratos da situação caótica, ao menos de acordo com o redator, em que viviam muitos daquela época. Um desses retratos é o texto de Is 52,13 - 53,12 do qual nos interessa somente uma parte.

A cena de Is 53,2-3 trata de um homem que é, porém, desfigurado,

habita numa sociedade, mas desprezado; às dores e aos sofrimentos corporais junta-se o abandono dos outros, que interpretam o sofrimento como castigo de Deus, e temem contagiar-se caso cheguem perto dele, e cobrem-se a face para se protegerem dele. Ou então de acordo com outra tradução, é ele que se cobre a face envergonhado ${ }^{4}$.

Esse chamado quarto cântico do servo sofredor muitas vezes foi ligado à figura de Jesus pelo seu caráter expiatório ${ }^{5}$ pois, de fato, os evangelhos quando escrevem a paixão de Cristo se inspiram nesse texto.

3 Cf. RICCIOTTI, Giuseppe. Storia d'Israele: Dall'esilio al 135 dopo Cristo. Torino: Società Editrice Internazionale, 1964. p. 80-81.

4 ALONSO SCHÖKEL, Luis; SICRE DÍAZ, José L. Profetas, I, Isaías, Jeremias. Trad. Anacleto Alvarez. São Paulo: Paulinas, 1988. p. 341.

5 Cf. JINTAE, Kim. "Targum Isaiah 53 and the New Testament Concept of atonement", JGRChJ 5 (2008), p. 81-98. 


\subsection{Alguns aspectos exegéticos de Is 53,2-3}

A forma consuetudinária de exame de um texto bíblico prevê a análise das variantes textuais (critica textus), o estudo da semântica, gramática e estrutura da perícope, uma abordagem do contexto bíblico e uma hermenêutica baseada nos elementos precedentes.

Dentre as variantes textuais nos diversos manuscritos antigos podemos sublinhar duas, uma em cada versículo.

No v. 2, o texto hebraico "cresceu diante dele" (lefanaw) possui a leitura variante "diante de nós" (lefaneynw). Como o hebraico é uma língua predominantemente consonantal, a mudança é só de uma consoante, o que modifica da terceira pessoa singular (ele) para a primeira do plural (nós). Nesse caso, o texto grego dirime a questão pois lê autou (dele).

No v. 3, enquanto o texto massorético (TM) lê o particípio nifal nibzeh (desprezado), um texto de Qumran (1QIs $\left.{ }^{a}\right)$ lê a forma ativa wnbwzhw (nós o desprezamos). Essa interpretação, segundo Berges, provavelmente é decorrente da formula final "nós o tivemos por um

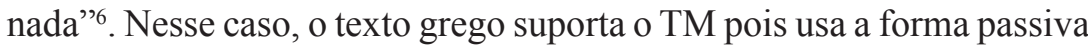
do verbo (etimasthe), motivo pelo qual sustentamos o TM.

No que se refere ao esquema literário da perícope, segundo Watts o cântico é composto em forma de quiasmo e diviso no seguinte modo A $(52,13)$ B (52,14-15) C (53,1-2) “Pedra angular" (53,3-6) C' (53,7-9) B' $(53,10-11) A^{\prime}(53,12)^{7}$. Esse tipo de construção evidencia a mensagem central que se posiciona justamente no centro do texto: o servo desprezado e que leva consigo a iniquidade de todos. Em nosso caso, o interesse se concentra somente em Is 53,2-3.

O v. 2 se abre com uma típica estrutura literária hebraica, um paralelismo. Nesse, o servo é comparado a duas coisas: um rebento e uma raiz. Considerando que tais termos aparecem em sequência, formando justamente um paralelo, eles possuem a função de intensificar a ação, acentuando ainda mais o fato que o servo tenha se destacado, ou germinado, em modo improvável até então.

\footnotetext{
Cf. BERGES, U. Jesaia 49-54, HThKAT, Stuttgart: Verlag Herder, 2015. p. 214.

7 Cf. WATTS, John D. A. Isaiah 34-66, Word Biblical Commentary 25, Waco: Word Books, 1987. p. 229. Uma hipótese alternativa sugere cinco estrofes $(52,13-15 ; 53,1-3 ; 4-6$; 7-10a $;$; 10aß-12) (cf. BERGES, U. Jesaia 49-54, HThKAT, Stuttgart: Verlag Herder, 2015. p. 220).
} 
A imagem do "rebento em terra árida" é uma figura usada para se referir a um parente que não está na linha de sucessão do trono. Se a premissa é verdadeira, nesse caso o texto poderia fazer uma alusão ao rei Dario, da Pérsia ${ }^{8}$.

Mas o problema da identidade do servo, ou rebento, não se resolve facilmente. $\mathrm{O}$ texto poderia ter feito uma referência ao rei da Babilônia, segundo uma hipótese ${ }^{9}$. Ou esse seria uma alusão velada ao profeta que estava discorrendo sobre a sua própria experiência de perseguição, narrando os maus tratos que sofrera. Ou ainda o autor do texto estaria falando em nome de Israe ${ }^{10}$. Tal tese é corroborada pelo fato de que todo o texto de Is 53,1-10 é permeado por diversos "nós". O significado desse plural poderia estar em Israel ou, numa leitura mais universalizante, em toda a humanidade ${ }^{11}$.

Por outro lado, a interpretação do servo vinculado ao ambiente régio nos oferece uma pista para a interpretação, pois se trata de uma pessoa de origem nobre e que é desprezada. No fundo esse é o retrato de todo ser humano, que nasce "nobre", isto é, é filho de Deus ${ }^{12}$, mas nem sempre é tratado como tal.

$\mathrm{O}$ v. 2 continua com uma série de três negações, das quais é pertinente notar a locução preposicional "nele" e o pronome possessivo "nossa": "não havia aparência NELE", "não tinha beleza para atrair NOSSA visão", "não tinha aspecto para ser desejado NELE".

Considerando somente a estrutura desse versículo já é possível concluir que existe um aspecto objetivo, que é um limite do servo em si, isto é, não é belo. Por outro lado, existe um fator subjetivo, isto é, ele

8 Cf. WATTS, John D. A. Isaiah 34-66, Word Biblical Commentary 25, Waco: Word Books, 1987. p. 230.

9 Cf. KIRCHHEVEL, Gordon D. "Who's Who and What's What in Isaiah 53", BBR 13.1 (2003) p. 128-129.

10 Cf. MCKENZIE, John L. Second Isaiah, The Anchor Bible, New York: Doubleday, 1968. p. 132; cf. STEINMANN, J. O livro da consolação de Israel e os profetas da volta do exílio. Trad. Monjas da Abadia de Nossa Senhora das Graças. São Paulo: Paulinas, 1976. p. 193.

11 WIÉNER, Claude. O Dêutero-Isaías: o profeta do novo êxodo. Trad. José Raimundo Vidigal. 2. ed. São Paulo: Paulinas, 1984. p. 74.

12 A filiação divina que recebemos no batismo não significa que deva ser entendida como exclusiva prerrogativa cristã. Em sentido genérico o não batizado também pode se referir a Deus como Pai, como ocorre, por exemplo no Antigo Testamento (cf. Dt 32,6; MI 2,10; Jr 31,9 et al.) 
não atrai a nossa atenção. O centro da questão emoldurada pelo "nele", portanto, é a "nossa" visão em confronto deste ser marginalizado.

Não havia to'ar (aparência) nele (v.2). O substantivo to'ar é utilizado diversas vezes como sinônimo de formosura humana (cf. Gn 29,17;39,6; Dt 21,11; $1 \mathrm{Sm} 16,18 ; 23,3 \ldots$ ), animal (cf. Gn 41,18) ou de um fruto (cf. Jr 11,16). Seu equivalente na Septuaginta é eidós, e o significado tem a ver com "esboço, forma, aparência; vulto, dignidade"13. Sua imagem, portanto, não serve para ser idolatrada (eidos-latria), ou seja, não serve de modelo para ninguém.

Como se isso não bastasse, o servo sofredor do cântico também não possui outra característica: a beleza (hadar) (v. 2). Curiosamente a versão grega dessa palavra varia muito, podendo ser: horaios (Lv 23,40), kalós (Dt 33,17), megalopreteias (S1 145,5.12) ou timé (Is 35,2). É utilizada para falar ou de Deus ou das coisas por ele abençoadas. Daí decorre que sua ausência pode significar uma distância em relação à bênção divina. Assim ocorre, por exemplo, no livro de Jó ${ }^{14}$.

Um paralelo interessante em que se encontram unidas as palavras "aspecto" e "desejo" (Is 53,2) é Gn 2,9, em referência às arvores criadas por Deus. Dentre essas estava a árvore do conhecimento que se apresenta a Eva como "sedutora aos seus olhos" (Gn 3,6). A beleza que atrai nossa atenção, portanto, nem sempre leva a um final feliz.

No início v. 3 se diz que esse homem é "desprezado", verbo que se repete ao fim do mesmo versículo. A função comunicativa da repetição é mais que uma técnica mnemônica, ela pretende também sublinhar esse elemento como importante. A versão grega do texto é ainda mais incisiva quando diz que ele é desprezado por "TODOS os homens", em contraste com o hebraico que diz somente "homens", sem o uso do pronome indefinido.

Esse sujeito é denominado com a hendíade "homem sofredor". Embora essa expressão seja única na Bíblia, é possível concluir em base à estrutura da língua hebraica que o texto queira dizer simplesmente

13 VV. AA. Dicionário Hebraico-Português e Aramaico-Português. 12. ed. São Leopoldo: Sinodal; Petrópolis: Vozes, 2000. p. 264.

14 O livro de Jó retrata o homem justo e próspero que perdeu tudo e teve sua fé provada, passando de uma teologia da prosperidade baseada no do ut des (dou para que me dês) a uma teologia do amor gratuito. 
"sofredor" ". O texto não deixa claro de qual tipo de sofrimento o nosso protagonista é vítima: uma doença, ou tudo é fruto de uma violência física? Segundo McKenzie, ele recebe todo tipo de sofrimento ${ }^{16}$.

O cântico ainda continua dizendo "nós o tivemos por nada (lo hashab)". O verbo no Qal tem o sentido de "estimar, valorizar, considerar, tomar por, atribuir, reputar, planejar, intencionar, pensar, refletir, inventar" ${ }^{17}$. Como o texto hebraico permite, pode-se dizer que a figura em questão é a negação (lo) de todos esses verbos supracitados.

O texto de Is 53,2-3, portanto, nos revela a imagem de um ser humano desprezado por todos. O deserto infértil e árido no qual germina lhe é sempre hostil sem dar-lhe nem uma gota d'água para sustentá-lo. Uma planta que nasce nessas condições é muito diversa daquela que floresce perto de um curso d'água, como aquela descrita pelo profeta Jeremias, cujas folhas são sempre verdes e que não teme o calor (cf. Jr 17,7-8).

Diante desse ser que sofre sem aparência nem beleza nosso olhar se desvia para focalizar em algo mais prazeroso e menos repugnante. Além de fechar os olhos, cobrimos a nossa face para evitar que tenhamos a tentação de enxergar essa dura realidade. Quantas barreiras nós impomos entre nós e esse servo que representa toda a humanidade sofredora e excluída da sociedade!

A plena compreensão do quarto cântico do servo ocorre somente muitos séculos depois de sua escrita. Jesus assumiu a nossa condição humana, passando pelas experiências que todos nós passamos "exceto o pecado" (cf. Hb 4,15). Isso significou passar pelos sofrimentos mundanos, em unidade com todos os que sofrem a paixão no quotidiano. Por isso, desde os Evangelhos e também At 8,32ss a perícope de Is 53 é interpretada alegoricamente como uma profecia acerca do Messias que deveria sofrer.

Jesus, em sua morte tão vilipendiada, não maldiz, não acusa, não implora, mas absorve dentro de si todo o negativo ${ }^{18}$. O passo seguinte

15 Sobre esse tipo de hendíade, cf. Gn 6,9 (homem justo=justo); Gn 11,7 (homem juíz=juíz)...

16 Cf. MCKENZIE, John L. Second Isaiah, The Anchor Bible, New York: Doubleday, 1968. p. 133.

17 VV. AA. 2000, p. 79.

18 Cf. BAGGIO Apud CAMBÓN, Enrique. Trinità modello sociale. 3. ed. rivista e aggiornata. Roma: Città Nuova, 2009. p. 181. 
operado pelo Redentor, ao ressuscitar, foi trazer para fora somente o positivo. Por isso, n'Ele, o pobre sofrido faz a experiência de retornar à beleza original, isto é, aquela perdida na criação.

Todo ser humano foi criado à imagem (selem) e semelhança (demut) de Deus. O significado disso está muito bem expresso por Stadelmann:

selem (imagem) de ordem natural, demut (semelhança) de ordem sobrenatural. O homemé, pois, a única criatura dotada de graça santificante. Ela qualifica o ser no âmbito ontológico, e o agir no âmbito ético, social e religioso, onde o homem se torna o interlocutor idôneo no diálogo com Deus ${ }^{19}$.

Nesse sentido, os pobres que labutam diante das opressões do mundo, que têm sua beleza roubada, que vivem como se nada significassem, podem inspirar-se no servo sofredor. Seu sofrimento, porém, não é resignado, mas é convicto: para que aconteça a libertação, vale a pena inclusive abrir mão da própria vida.

O "silêncio militante" do servo é uma categoria nova que ele nos ensinou. Diante dele as grandes potências humanas sentem-se inócuas. Basta lembrar, ao longo da história, grandes personalidades que suportaram o cárcere e a perseguição no mais absoluto silêncio. Em sua ausência de palavras, porém, ecoava o mais eloquente grito de libertação.

Diante disso, é mister trilhar um pequeno itinerário em busca da beleza que se esconde no pobre. No silêncio militante vislumbra-se a grandeza de Deus que se revela em cada uma de suas criaturas. Aos poucos, as trevas incolores dão lugar ao mais puro arrebol, pleno de vigor luminoso.

\section{Desvelando a beleza no pobre}

Quando assistimos a algum filme, ou programa de TV, ou ainda temos em mão alguma propaganda publicitária, salta aos olhos a beleza das imagens. O máximo de feiura que podemos encontrar nesses slogans aparece somente como contraste do Belo que está sendo oferecido. Assim, temos como ideal de beleza o que é apresentado a nós para ser seguido

19 STADELMANN, Luís I. J. Criação e ecologia na Bíblia. São Paulo: Loyola, 2007. p. 60. 
como paradigma. Quem não se enquadra definitivamente nisso são os pobres. Nas palavras de Enrique Dussel,

a aparente feiura do pobre vista como caótica presença pela beleza do sistema, da Totalidade, pela beleza cultural imperante, é exatamente a interpelação com exigência de justiça (porque a aristocrática estética imperante é sempre injusta: aquela que por exemplo mede o valor da beleza latino-americana a partir dos moldes europeus ou norte-americanos) da beleza futura, real e meta-fisica de alguém que enquanto mistério oculto, não revelado, para além de sua ôntica apresentação num museu ou exposição, já vive numa ordem humana na esperança. A aparente feiura do pobre [...] não é mais do que a máscara cuidadosamente trabalhada pela opressão dos dominadores e com a qual se esconde a beleza do Outro, do homem livre que é a índia, a criança, o trabalhador, para que não apareça a visão falseada do mundo dos poderosos ${ }^{20}$.

Aqui fica patente que, para sair do esquema de dominação, urge des-cobrir o que há de belo por trás do que o pobre aparenta. Para isso é mister que haja um cuidado em relação a ele. E nisso reside um dos entraves desse processo.

O cuidado exige que se tenha com o outro a mesma atenção que seria destinada a alguém mais abastado. A experiência mostra que, na maioria das vezes, quando vemos um pobre caído à beira do caminho não o ajudamos. Por outro lado, um "cidadão" bem vestido que tropeça é subitamente acudido pelos que o rodeiam. Uma antiga prática que já fora denunciada nas primeiras comunidades cristãs por São Tiago. O apóstolo critica o rebanho de seu tempo pela sua prática de favoritismo, que acolhe quem usa um anel de ouro e ricas roupas com solenidade, enquanto o pobre não encontra nem mesmo um posto para se sentar (cf. Tg 2,2ss). Tudo isso porque a beleza dos ricos nos atrai mais que a simplicidade dos pobres.

Para revelar a beleza do pobre é preciso limpá-lo, curar suas feridas (cf. Lc 10,34), dar-lhe roupas novas, por um anel em seus dedos, dar-lhe sandálias novas (cf. Lc 15,22), enfim, reconhecê-lo em sua dignidade. Tudo isso, é claro, na dinâmica do tu a tu, isto é, num relacionamento entre sujeitos, e não de um simples relacionamento epistemológico entre um sujeito e um objeto.

20 DUSSEL, Enrique. Para uma ética da libertação Latino-Americana: Erótica e pedagógica. V. 3. Trad. Luiz João Gaio. São Paulo: Loyola; Piracicaba: Unimep, 1977. p. 95. (grifos do autor). 
Mas além desse aspecto filantrópico que é importante, talvez o que mais temos dificuldade é de reconhecer a beleza no outro para além de suas aparências. Nesse sentido, mesmo um maltrapilho e fedido mendigo que bate à nossa porta deveria ser reconhecido em sua dignidade, independentemente do fato de estar vestido ou não de acordo com tal prerrogativa. Um passo difícil, mas se pensarmos bem, é assim que Deus nos vê: sem os nossos pecados, sem os nossos limites, mas vê o que temos de melhor procurando fazer-nos descobrir e manifestar a todos o nosso melhor. E como Jesus nos ensinou, devemos amar-nos uns aos outros como Ele nos ama (cf. Jo 15,12).

Infelizmente, quem detém o poder econômico geralmente pensa que tudo pode comprar. E continua a acumular sempre mais em um ciclo insaciável. Como disse Schopenhauer, "a riqueza é semelhante à água do mar: quanto mais se bebe, mais se tem sede" ${ }^{21}$.

Como o dinheiro dá uma sensação de onipotência inclusive sobre as pessoas, essa dinâmica leva muitos pobres a degradarem sua beleza tornando-a objeto que pode ser comprado. Isso acontece, dentre outras situações, na prostituição ${ }^{22}$ : "A palavra grega pórne procede do verbo pérnemi que significa vender, alienar, e em seu sentido radical: vender uma escrava, uma mulher. É $o$ ato sexual que significa a instrumentação da mulher"23.

A prostituição é uma das profissões mais antigas do mundo e aceita normalmente por muitas sociedades desde as mais antigas ${ }^{24}$ até as mais recentes vitrines nas quais se expõem as mulheres como produtos para serem comprados. O preço de alguns minutos de prazer é a objetificação de uma pessoa que deveria ser tratada como um sujeito.

21 SCHOPENHAUER, A. La saggezza della vita: aforismi, a cura di Leonardo Casini, Milano: Hachette, p. 64.

22 Com isso, estamos nos referindo às práticas que degradam sobretudo os mais pobres que buscam nessa atividade uma forma de sair de sua situação miserável. Porém, estamos cientes de que existem redes de prostituição nas quais as mulheres ganham quantias de dinheiro significativas e talvez até considerem sua profissão louvável. Por isso, não está em questão os que optaram deliberadamente, tendo outras possibilidades, mas os que não encontraram outra saída senão a da venda de seu corpo.

DUSSEL, 1977, p. 131.

24

Por exemplo, no texto de Demóstenes, IV séc. a.C., o autor fala com naturalidade "nisso consiste a convivência matrimonial (synoikein), em fazer filhos com ela (a mulher), apresentá-los aos frateros e aos demotas como filhos legítimos e em fazer com que as filhas se casem como filhas próprias. Nós temo as cortesãs (hetairas) para o nosso prazer, as concubinas (palakkas) para o nosso cuidado quotidiano de nosso corpo, as mulheres (gynaikas) para a procriação da prole legítima e para ter uma fiel guardiã do lar" (Demosth., In Neaeram, 122). 
Quando conseguimos ver a beleza do outro e, nesse caso, não só aquela beleza concupiscente, deixamos de ser tiranos e nos tornamos magnânimos. Vale notar a definição de "tirano" apresentada por Camus: "[...] é um homem que sacrifica as pessoas à suas ideias e à sua ambição" ${ }^{25}$. Portanto, quando se tem diante de si somente ideias despóticas e ambição, não resta espaço para perceber que, além da vaidade egoísta, existe algo que me atrai no outro. Por isso, ele não pode ser relegado à margem nem comprado por nenhum preço.

É a experiência da beleza no outro que nos desperta, como diz Plotino, "o amor do belo em si em toda sua pureza e põe a alma em marcha para sua pátria"26. Nesse sentido, é cabível o desejo expresso pelo literato e teólogo Rubem Alves: "Quero uma teologia que esteja mais próxima da beleza que da verdade, porque da visão da beleza surgem os amantes, mas sobre a convicção da verdade se constrói (sic) as inquisições" ${ }^{27}$.

Por isso, na lógica do mesmo autor,

a beleza é o contraponto do sofrimento. A beleza não anula o sofrimento nem o sofrimento é capaz de anular a beleza. Mesmo que a beleza não anule o sofrimento, ela fará o ser humano enxergar além dele e da morte, por meio da construção de uma teia de significados que revele a efemeridade do próprio sofrimento. O ser humano necessita da beleza para viver sua vida ${ }^{28}$.

Não há mais espaço na teologia para o véu da ignorância. Se no Antigo Testamento o véu cobria a beleza de Deus restringindo-a aos eleitos, com Jesus é diferente. Sua morte na cruz tornou o templo do seu corpo aberto à humanidade: suas vestes foram rasgadas (cf. Mt 27,35) e, de modo similar, rompeu-se o véu do templo (cf. Mt 27,51). O sentido é claro: o mistério da beleza divina foi desvelado a nós. A mesma beleza é encontrada, sobretudo, nos pobres e aflitos, como nos recorda o Juízo final de Mateus "todas as vezes que fizeste uma dessas coisas a um só desses pequeninos, a mim o fizeste" (Mt 25,40).

25 «un tyran est un homme qui sacrifie des peuples à ses idées ou à son ambition» (CAMUS, Albert. Caligula. Gallimard: Barcelona, 2012.) (Tradução nossa).

26 Cf. LACOSTE, Jean-Yves. Dicionário Crítico de Teologia. Trad. Paulo Meneses et al. São Paulo: Loyola; Paulinas, 2004. p. 273.

27 ALVES, Apud REBLIN, luri A. In: VV. AA. A teologia contemporânea na América Latina e no Caribe. São Leopoldo: Oikos; EST, 2008. p. 152.

28 ALVES, Apud REBLIN, luri A. In: VV. AA. A teologia contemporânea na América Latina e no Caribe. São Leopoldo: Oikos; EST, 2008. p. 152. 


\section{Considerações Finais}

Quando pensamos nos sofrimentos dos mais pobres não devemos ter o olhar de "pena", isto é, que vê o outro como uma aberração. Numa célebre metáfora da existência humana, Kafka mostra a transformação do homem em uma criatura desprezível. Diante de tal cena chocante, o único alívio que os familiares da vítima experimentaram foi quando ela morreu ${ }^{29}$. Nesse caso, nem mesmo os seus conseguiram ver a beleza além das aparências.

O olhar a que nos propomos é inspirado no modo como o servo sofredor lida com a degradação humana. Seu silêncio militante não permite a resignação, mas convoca à práxis libertadora. No pobre maltratado pela sociedade que o ridiculariza caçoando de sua feiura, na verdade está o rosto de Jesus que é o belo/bom (kalós) pastor (cf. Jo 10,11). O mesmo que afirmou que seria encontrado nos menos favorecidos (cf. Mt 27,35-36). E o mesmo que nos ensina a ver o outro como imagem e semelhança de Deus (cf. Gn 1,26). Termino com uma citação do escritor italiano do século XIX, Aleardo Aleardi:

"Digam-me, ó belas luzes, digam-me o que é Deus?"

- "Ordem"- me respondem as estrelas.

Quando em abril o vale, o monte, o prado, as margens do rio, cada campo é festejado com flores, olho e pergunto: "digam-me, ó cores belas, digam-me o que é Deus?"

- "Beleza" - me respondem aquelas flores.

Quando o teu olhar cintila diante de mim, amavelmente pio, eu pergunto à luz de tua pupila: "Diga-me, se sabes, belo mensageiro do coração, diga-me o que é Deus?”

E a pupila me responde: "Amor"30.

29 Cf. KAFKA, Franz. La metamorfosi. Trad. italiana Luigi Coppé. Newton Compton: Milano, 2013.

30 "Dite, o luci belle, Ditemi cosa è Dio?" - "Ordine" - mi rispondono le stelle. Quando all'april la valle, il monte, il prato, i margini del rio, ogni campo dai fiori è festeggiato, Guardo e dimando: Dite, o bei colori, ditemi cosa è Dio? - "Bellezza" - mi rispondono quei fiori. Quando il tuo sguardo inanzi a me scintilla, amabilmente pio, io chiedo al lume della tua pupilla: "Dimmi, se il sai, bel messaggier del core, dimmi che cosa è Dio?" E la pupilla mi risponde: - "Amore". ALEARDO ALEARDI, Canti, e-book, p. 470. 


\section{Referências}

ALONSO SCHÖKEL, Luis; SICRE DÍAZ, José L. Profetas, I, Isaías, Jeremias. Trad. Anacleto Alvarez. São Paulo: Paulinas, 1988.

ALVES, Apud REBLIN, Iuri A. In: VV. AA. A teologia contemporânea na América Latina e no Caribe. São Leopoldo: Oikos; EST, 2008.

BERGES, U. Jesaia 49-54, HThKAT, Stuttgart: Verlag Herder, 2015.

CAMBÓN, Enrique. Trinità modello sociale. 3. ed. rivista e aggiornata. Roma: Città Nuova, 2009.

CAMUS, Albert. Caligula. Gallimard: Barcelona, 2012.

DEMOSTENE. Processo a una cortigiana (Contro Neera), a cura di Elisa Avezzù. Il Convivio, Venezia 2002 ${ }^{4}$.

DUSSEL, Enrique. Para uma ética da libertação latino-americana: Erótica e pedagógica. V. 3. Trad. Luiz João Gaio. São Paulo: Loyola; Piracicaba: Unimep, 1977.

HÖVER-JOHAG, I., “טוב", GLAT, III, 367-394.

JINTAE, Kim. "Targum Isaiah 53 and the New Testament Concept of atonement”, JGRChJ 5 (2008), p. 81-98.

KAFKA, Franz. La metamorfosi. Trad. italiana Luigi Coppé. Newton Compton: Milano, 2013.

KIRCHHEVEL, Gordon D. "Who's Who and What's What in Isaiah 53”, BBR 13.1 (2003) p. 127-131.

LACOSTE, Jean-Yves. Dicionário Crítico de Teologia. Trad. Paulo Meneses et al. São Paulo: Loyola; Paulinas, 2004.

MCKENZIE, John L. Second Isaiah, The Anchor Bible, New York: Doubleday, 1968.

RICCIOTTI, Giuseppe. Storia d'Israele: Dall'esilio al 135 dopo Cristo. Torino: Società Editrice Internazionale, 1964.

SCHOPENHAUER, A. La saggezza della vita: aforismi, a cura di Leonardo Casini. Milano: Hachette.

STADELMANN, Luís I. J. Criação e ecologia na Bíblia. São Paulo: Loyola, 2007. 
STEINMANN, J. O livro da consolação de Israel e os profetas da volta do exílio. Trad. Monjas da Abadia de Nossa Senhora das Graças. São Paulo: Paulinas, 1976.

VV. AA. Dicionário Hebraico-Português e Aramaico-Português. 12. ed. São Leopoldo: Sinodal; Petrópolis: Vozes, 2000.

WATTS, John D. A. Isaiah 34-66, Word Biblical Commentary 25, Waco: Word Books, 1987.

WIÉNER, Claude. O Dêutero-Isaías: o profeta do novo êxodo. Trad. José Raimundo Vidigal. 2. ed. São Paulo: Paulinas, 1984. 